\title{
DESONERAÇÃO DA CESTA BÁSICA OU EXPANSÃO DO PROGRAMA BOLSA FAMÍLIA? UMA SIMULAÇÃO POR EQUILÍBRIO GERAL COMPUTÁVEL
}

\author{
Ewerton Melo Araújo ${ }^{a}$ \\ Nelson Leitão Paes ${ }^{b}$
}

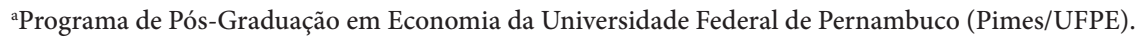
Recife, PE, Brasil. ORCID: https://orcid.org/0000-0002-1574-7452.

bPrograma de Pós-Graduação em Economia da Universidade Federal de Pernambuco (Pimes/UFPE) e Programa de Pós-Graduação em Economia da Universidade Federal do Mato Grosso (FE/UFMT). Cuiabá, MT, Brasil. ORCID: https://orcid.org/0000-0001-6246-4503.
\end{abstract}

Artigo recebido em 29/09/2017 e aceito para publicação em 05/12/2018.

RESUMO: Com o objetivo de reduzir a pobreza, a partir do ano de 2013 o governo brasileiro promoveu a desoneração da cesta básica e aumentou o valor do Programa Bolsa Família (PBF). Este trabalho busca analisar qual das duas opções de política teria maior impacto sobre as famílias mais pobres caso os recursos destinados às duas fossem iguais. Em seguida buscou-se verificar qual nível de focalização requerido para o PBF igualaria os impactos das duas políticas. Para tanto se construiu um modelo de equilíbrio geral com tempo discreto e famílias heterogêneas. Os resultados mostram que a elevação das transferências gera maior benefício sobre o bem-estar da classe mais pobre do que a desoneração da cesta básica. Tal resultado se mantém para um nível de focalização do PBF a partir de 35,4\%. Para níveis de focalização menores que esse, a desoneração da cesta básica passa a ser preferível.

PALAVRAS-CHAVE: Bolsa Família; desoneração da cesta básica; nível de focalização; equilíbrio geral computável.

CLASSIFICAÇÃO JEL: H21; H23; H55.

Correspondência para: Ewerton Felipe de Melo Araújo

Contato: ewertonfma@gmail.com 


\section{TAX EXEMPTION OF THE BASIC FOOD BASKET OR EXPANSION OF THE BOLSA FAMÍLIA PROGRAM? A COMPUTABLE GENERAL EQUILIBRIUM SIMULATION}

ABSTRACT: In order to reduce poverty, from 2013 onwards, the Brazilian government promoted the exemption of the basic food basket and increased the value of the Bolsa Família Program (PBF). This paper seeks to analyze which of the two policy options would have greater impact on the poorest households if the funds for the two were equal. Next, it was calculated which level of targeting required for the PBF would equal the impacts of the two policies. For this purpose a general equilibrium model was built with discrete time and heterogeneous households. The results show that the increase of the transfers generates greater benefit on the welfare of the poorer class than the relief of the basic basket. This result is maintained at a target level of PBF at least $35.4 \%$. For lower levels of targeting, the relief of the basket becomes preferable.

KEYWORDS: Bolsa Família; tax relief; focalization level; computable general equilibrium. 


\section{INTRODUÇÃO}

Um dos papéis primordiais do governo é o combate à miséria e a garantia dos direitos fundamentais da população, sendo o direito à alimentação básica o seu principal pilar. Em um país em desenvolvimento como o Brasil, que ainda sofre com o problema da pobreza, principalmente em suas regiões menos industrializadas, é essencial a tomada de medidas eficientes que ajudem a reduzir o problema.

No caso brasileiro destacam-se duas opções de política com o objetivo de reduzir a pobreza: a redução dos impostos para bens com maior peso na cesta de consumo das famílias de baixa renda e a elevação dos benefícios sociais concedidos às camadas mais pobres da população.

Em março de 2013 o Governo Federal promoveu a redução a zero das alíquotas de contribuição para o PIS/Pasep, Cofins e IPI de todos os produtos pertencentes à cesta básica (para alguns a alíquota já era zero). A medida foi tomada com o intuito de reduzir preços e facilitar o acesso a produtos básicos de alimentação pelas classes de baixa renda.

Nesse mesmo ano, a partir de $1^{\circ}$ de junho, o Governo Federal redefiniu os valores limites das linhas de pobreza e extrema pobreza no Brasil, que passaram de R $\$ 70,00$ para $\mathrm{R} \$ 77,00$ mensais per capita. Com isso o valor dos benefícios do Programa Bolsa Família (PBF) aumentou na mesma magnitude. Segundo o Ministério do Desenvolvimento Social (MDS), a medida representa uma elevação de R\$1,7 bilhão em 2014 e R\$ 2,7 bilhões em 2015 nos gastos com o programa.

$\mathrm{O}$ aumento do PBF ganha destaque pelo viés político que lhe é atribuído, pois ao longo da última década o programa ganha a cada dia mais importância, tornando-se um dos principais trunfos do Governo Federal no combate à pobreza. Autores como Oliveira et al. (2011), Glewwe e Kassouf (2012) e Mourão, Ferreira e Jesus (2012) sugerem efeitos positivos sobre a educação, a nutrição e o bem-estar das classes baixas, apontando o programa como um elemento eficiente contra a pobreza.

Por outro lado, Gomes (2001), Tupy e Toyoshima (2013) e Araújo e Lima (2009) mostram a grande dependência que determinadas regiões do País têm em relação ao programa, e apontam como principal fator a falta de mecanismos que incentivem os beneficiários a sair da situação de pobreza.

Nota-se que o debate entre apoiadores e críticos do PBF é intenso, não só na área acadêmica, mas também dentro da sociedade como um todo. Castro et al. (2009) realizam uma análise do programa sob um ponto de vista social, estudando como a população julga tal política cinco anos após sua criação. Seus resultados apontam apoio da maior parte da população, apesar de haver críticas quanto à fiscalização do programa. Outra consideração interessante é que indivíduos que conhecem pessoalmente algum beneficiário tendem a ser mais cautelosos nas críticas e a apoiar mais a política. 
No entanto, a transferência direta de renda sofre com o problema da falta de focalização, que ocorre quando uma família que não cumpre os requisitos obrigatórios consegue receber o benefício. Tais casos podem aparecer tanto devido à corrupção por parte dos servidores públicos responsáveis pelo processo (desde o cadastro até o pagamento das famílias) ou devido às famílias que cumpriam os requisitos, mas, após perderem o direito, não informaram as autoridades e continuam recebendo o benefício.

Independentemente do que causa a irregularidade, é gerada uma ineficiência, uma vez que existem famílias que se encaixam no perfil do recebedor e não recebem do PBF, enquanto famílias em condições melhores utilizam os recursos. Soares, Ribas e Soares (2009) discutem o tema e mostram que a focalização do programa se reduziu depois do aumento no valor de seus recursos no ano de 2006.

Em contraponto à transferência direta está a desoneração fiscal, que surge devido ao consenso de que a carga tributária brasileira é uma das mais elevadas do mundo, além de ter um caráter complicado e regressivo, como discutem Paes e Bugarin (2006).

Dadas essas circunstâncias, este trabalho busca primeiramente analisar qual das duas opções de política tomadas recentemente teria maior impacto sobre a redução da pobreza caso os recursos destinados a elas fossem iguais. De posse desses resultados segue-se para um segundo objetivo - verificar qual nível de focalização requerido para o $\mathrm{PBF}$ iguala os impactos das duas políticas, ou seja, qual focalização necessária no programa de transferência de renda que torna às famílias elegíveis ao programa indiferente receber a desoneração da cesta básica ou o aumento no programa bolsa-família.

Van Der Noord e Heady (2001) discutem o tema de forma bastante semelhante a este trabalho, argumentando teoricamente que a política de desoneração fiscal tem o problema de não se restringir às classes baixas. Como têm renda maior, as classes altas consomem uma quantidade maior dos bens desonerados, apoderando-se do benefício gerado pela política. Por ser destinada aos mais pobres, a eficiência da transferência direta é bem maior no quesito redistribuição de renda.

Dessa forma será construída uma economia artificial baseada no modelo neoclássico de Ramsey com tempo discreto e famílias heterogêneas. Essa economia será composta por dois tipos de famílias, as que possuem direito ao benefício e as que não possuem. Após a calibração do modelo para os dados da economia brasileira, serão realizadas simulações que reproduzirão as políticas discutidas aqui.

Na primeira simulação será feita uma redução nos impostos indiretos sobre a cesta básica nos moldes daquela realizada pelo governo em 2013. Na segunda simulação promove-se uma elevação no montante gasto com o PBF de valor equivalente à queda na arrecadação gerada na primeira política.

Além desta introdução o artigo apresenta mais seis seções. Na seção 2 será discutido o Programa Bolsa Família, suas condicionalidades e os principais trabalhos que 
tratam de seus pontos positivos e negativos. A seção 3 abordará a tributação e os impactos da política tributária sobre a pobreza, além de uma discussão comparativa entre as duas políticas aqui estudadas. A seção 4 apresenta o modelo utilizado, a estratégia de pesquisa e a natureza e fontes dos dados. A seção 5 mostra a calibração dos dados e o valor dos parâmetros utilizados no modelo. A seção 6 apresenta os resultados encontrados, e a seção 7 traz as considerações finais.

\section{REVISÃO DA LITERATURA}

\subsection{IMPACTOS ECONÔMICOS E SOCIAIS DO PROGRAMA BOLSA FAMÍLIA}

A política assistencialista do Governo Federal nos moldes atuais teve início em janeiro de 2004, quando o Programa Bolsa Família (PBF) promoveu a unificação do Programa Fome Zero e de diversos programas sociais implantados durante o governo Fernando Henrique Cardoso, dentre eles, o Bolsa Escola, Auxílio Gás, Bolsa Alimentação e o Cartão Alimentação.

Desde então, os efeitos do programa sobre a renda das classes baixas têm sido significativos, gerando forte apoio político ao programa vindo de uma parte da sociedade. Para os defensores da política, o benefício financeiro e as condicionalidades do programa atuam tanto elevando o poder de compra da camada pobre da sociedade quanto melhorando seus níveis educacionais e de saúde.

Segundo descrição do Ministério do Desenvolvimento Social e Combate à Fome (MDS), o PBF é um programa de transferência direta de renda com condicionalidades, que beneficia famílias consideradas em situação de pobreza (renda mensal per capita entre R\$77,01 a R \$ 154,00) e extrema pobreza (renda mensal per capita de até R \$77,00). Os principais objetivos do PBF são: combater a fome e promover a segurança alimentar e nutricional; promover o acesso à rede de serviços públicos, em especial de saúde, educação e assistência social; estimular a emancipação sustentada das famílias que vivem em situação de pobreza e extrema pobreza; combater a pobreza; e promover a intersetorialidade, a complementaridade e a sinergia das ações sociais do Poder Público.

Em $1^{\circ}$ de junho de 2013 o Governo Federal anunciou o aumento dos benefícios do Programa Bolsa Família, assim como o crescimento de seu alcance, o que geraria, segundo o MDS, um aumento total de R $\$ 1,7$ bilhão nos gastos públicos com o programa no ano de 2014.

O montante pago pelo PBF varia bastante de família para família. O valor básico para superação da extrema pobreza (pago apenas àqueles com renda mensal per capita inferior a $\mathrm{R} \$ 77,00)$ é de $\mathrm{R} \$ 77,00$. Aliado a este é possível acumular outros benefícios, 
dependendo da quantidade de crianças/adolescentes, gestantes e nutrizes na família. O recebimento também está atrelado ao cumprimento das condicionalidades, de forma que uma criança fora da escola, ou cujo cartão de vacinação não esteja atualizado, pode levar ao cancelamento do benefício.

Diversos trabalhos buscam avaliar os mais distintos impactos econômicos e sociais derivados da implantação do Programa Bolsa Família (PBF) nas diversas regiões do Brasil. Seus objetivos vão desde levantar evidências que testem a eficácia do programa em distribuir renda e elevar o capital humano da classe pobre até medir o quão grande é a fatia dos beneficiários que conseguem sair do programa (por meio de uma elevação produtiva de sua renda).

Silveira-Neto (2010) e Soares et al. (2010) são alguns dos autores que se dedicam a avaliar os impactos positivos do programa sobre áreas cruciais no campo social. $\mathrm{O}$ primeiro autor encontra efeito positivo do Programa Bolsa Família sobre a frequência escolar das crianças entre sete e 14 anos (de forma mais acentuada na região Nordeste). Já Soares et al. (2010) afirmam que o PBF foi responsável por $15 \%$ da redução verificada entre 1999 e 2009 no índice de Gini no Brasil, que caiu de 59,2 para 54,0; e por $16 \%$ da queda da pobreza (medida em relação à linha de $\mathrm{R} \$ 100,00$, de janeiro de 2004), que caiu de $26 \%$ para $14 \%$ da população nesse mesmo período.

Diferentemente da discussão apresentada anteriormente, Oliveira et al. (2011) estudam o impacto do programa na nutrição de crianças no estado de Minas Gerais. Os resultados mostram que, devido à relação positiva entre renda e acesso a alimentos e às condicionalidades impostas, o PBF leva a uma evolução no quadro nutricional infantil. Outro fator importante é que, com a elevação da renda, as famílias passam a ter acesso a melhores condições de higiene e saneamento básico, o que colabora para a redução de problemas de saúde.

Mourão, Ferreira e Jesus (2012) realizam testes estatísticos baseados em questionários aplicados à população de favelas do Rio de Janeiro e verificam diferenças significativas entre os grupos de beneficiários e não beneficiários, percebendo a importância do PBF no aumento do número de refeições diárias e renda familiar.

Por outro lado, os críticos apontam a falta de incentivos gerada pelo programa para a saída de seu quadro de beneficiários (gerando uma camada dependente), assim como o baixo estímulo do setor produtivo da economia. Gomes (2001) foi um dos primeiros a medir o quão dependente do setor público está a sociedade brasileira recente. Seu foco é em relação à elevada proporção da população que depende de aposentadorias, de outros benefícios sociais e de empregos públicos (principalmente nas prefeituras). Os resultados sugerem que, apesar de haver alguma dependência em relação a todos os tipos de benefícios, os programas de transferência direta ainda não representavam grande impacto na renda das famílias como fazem atualmente após a criação do Bolsa Família. 
Baseados no trabalho de Gomes (2001), Tupy e Toyoshima (2013) investigam, entre os anos de 2004 e 2009, os impactos dos programas governamentais de transferência de renda, incluindo o PBF, sobre a estrutura econômica da mesorregião do Jequitinhonha, localizada no estado de Minas Gerais. O objetivo foi avaliar a possível existência de um fenômeno chamado de "Economia sem Produção". Por meio de dados de painel, verificou-se que as transferências intergovernamentais correspondiam a quase a totalidade do orçamento disponível para as prefeituras, sendo superiores mais de 19 vezes à arrecadação de tributos, além de alguns municípios onde mais de $80 \%$ das famílias eram beneficiárias de algum programa federal.

Em relação ao emprego, Medeiros, Britto e Soares (2007) afirmam que o valor concedido pelo PBF, apesar de significativo na elevação da renda da família, seria insuficiente para estimular sua saída do mercado de trabalho, a menos que o trabalho em questão seja extremamente mal remunerado ou até mesmo insalubre.

Com relação à focalização do programa, deve-se levar em conta tanto os problemas relacionados à corrupção e desvios de verbas quanto fatores (apesar de também serem ilegais) mais relacionados às dificuldades administrativas de um programa de tamanha dimensão.

Tavares et al. (2009) estudam o nível de focalização do PBF utilizando duas medidas, a tradicional (porcentagem de famílias beneficiadas que realmente pertencem ao público-alvo), em que se calcula o valor de 53\% para a economia brasileira; e um método proposto por Anuatti-Neto, Fernandes e Pazello (2001), que considera simultaneamente medidas de alcance do programa e de sua precisão. Um primeiro resultado do trabalho é que o sucesso na focalização depende do orçamento disponível nos estados.

Dois cenários são considerados para a realização de simulações: no primeiro, o Governo passaria a utilizar o mecanismo de seleção chamado proxy means-test (PMT), que seleciona os beneficiários a partir de informações pessoais e familiares correlacionadas com a renda; no segundo cenário o mecanismo de seleção é mantido, enquanto o tamanho do programa é aumentado. A comparação entre as simulações mostra que haveria ganhos em termo de focalização caso o novo método de seleção fosse adotado.

Soares, Ribas e Soares (2009) estudam a focalização do PBF a partir do aumento de tamanho do programa ocorrido em 2006, em que o número de famílias beneficiárias passou para 11 milhões. Mostra-se que 54\% dos beneficiários realmente se encaixam no público-alvo. O trabalho aponta para perdas em termos de focalização, mas não conclui que estas são ocasionadas pelo aumento do tamanho do programa. Os autores tratam como grau de focalização o total de famílias que recebem o benefício tendo realmente direito a tal.

Os autores citam a volatilidade da renda das famílias mais pobres como um fator importante nos erros de focalização. Levando em conta esses erros, estima-se que, 
para que todo (ou quase todo) o público-alvo seja atendido, a expansão deve chegar a atingir um total de 15 milhões de famílias.

Silva et al. (2018), com dados da PNAD 2016, estimam a focalização do Programa Bolsa Família como o percentual de beneficiários entre os $20 \%$ e $40 \%$ mais pobres da população. Estimam que $62,3 \%$ dos beneficiários do PBF estão entre os $20 \%$ mais pobres e $88,7 \%$ estão entre os $40 \%$ mais pobres. Em seguida, comparam a focalização encontrada com outros programas na América Latina. A Tabela 1 resume os resultados.

Tabela 1 - Percentual de beneficiários entre os mais pobres: comparação entre programas de transferência condicionada de renda da América Latina

\begin{tabular}{lcc}
\hline País & Entre os $\mathbf{2 0} \%$ mais pobres & Entre os 40\% mais pobres \\
\hline Panamá & $74,9 \%$ & $93,9 \%$ \\
Peru & $66,7 \%$ & $88,8 \%$ \\
Brasil & $62,3 \%$ & $88,7 \%$ \\
México & $51,7 \%$ & $78,7 \%$ \\
Argentina & $51,8 \%$ & $78,0 \%$ \\
Uruguai & $42,2 \%$ & $72,3 \%$ \\
Equador & $46,8 \%$ & $71,9 \%$ \\
Chile & $42,4 \%$ & $71,0 \%$ \\
Colômbia & $40,5 \%$ & $70,6 \%$ \\
Bolívia & $27,0 \%$ & $51,8 \%$ \\
\hline
\end{tabular}

Fonte: Silva et al. (2018).

Como ressaltam Silva et al. (2018), a despeito da extensão territorial e do tamanho da população, o Programa Bolsa Família está entre os mais bem focalizados da América Latina.

\subsection{TRIBUTAÇÃO COMO ELEMENTO DE REDUÇÃO DA POBREZA}

A desoneração total dos produtos da cesta básica dos impostos indiretos foi outra política realizada pelo Governo Federal no ano de 2013, por meio da Medida Provisória n 609 que zerou as alíquotas PIS/Pasep, Cofins e IPI dos bens pertencentes à cesta básica que ainda não haviam sido zerados. Os bens contemplados por essa medida foram: carnes (bovina, suína, aves, peixes, ovinos e caprinos), café, óleo, manteiga, açúcar, papel higiênico, pasta de dentes e sabonete, o que gerou uma renúncia fiscal de R\$ 5,4 bilhões em 2013, segundo estimativa do DIEESE (2013).

O impacto esperado para esse tipo de desoneração é também o estímulo ao consumo, além do fato deque o barateamento dos alimentos atinge também as famílias não recebedoras do $\mathrm{PBF}$, de modo que uma fatia do valor destinado à política será entregue às famílias com mais recursos. 
Os efeitos de políticas tributárias, tanto de desonerações de alimentos quanto de insumos, são discutidos por autores como Santos e Ferreira Filho (2007), que analisam, por meio de simulações baseadas em um modelo de equilíbrio geral inter-regional calibrado para o ano de 2001, o efeito de dois tipos de políticas tributárias relativas a impostos indiretos: a redução dos tributos sobre alimentos e a desoneração dos principais insumos utilizados na agropecuária. As simulações apresentam resultados semelhantes, sendo a política de redução da alíquota sobre alimentos aquela com implicações mais intensas. $\mathrm{O}$ impacto negativo é a queda na arrecadação, que se torna a maior restrição à prática desse tipo de política.

Siqueira (1997) aponta resultados positivos no combate à pobreza quando são concedidos subsídios (ou programas de transferência de renda) às classes mais baixas para o consumo de alimentos financiados pela reforma dos demais impostos indiretos.

Santos, Vieira e Reis (2009) simulam, por meio de um modelo de equilíbrio geral computável (CGE), outras opções de políticas públicas além do PBF, e verificam seu efeito sobre a distribuição de renda. Os resultados apontam que o modelo do PBF é mais eficiente no quesito redução da desigualdade, tendo, inclusive, um efeito positivo no bem-estar das camadas pobres.

Já Paes e Siqueira (2008) realizam um exercício semelhante a esse, apesar de tratarem de diferentes opções de políticas. Os autores comparam a concessão de uma renda fixa universal e um imposto de renda negativo para famílias de baixa renda. Por meio de um modelo de equilíbrio geral obtém-se como resultado que o desempenho (em termos de combate à pobreza) da política de renda básica universal é superior ao do imposto negativo se seus custos de focalização forem superiores a $50 \%$.

Com uma abordagem mais teórica do tema, Van der Noord e Heady (2001) mostram que, devido ao maior volume consumido pelas classes mais altas, as políticas de desoneração de bens de consumo são menos eficientes no quesito redistribuição de renda do que a concessão de vouchers e transferência direta. A razão apontada é que estes têm um maior grau de focalização pelo fato de serem endereçados às classes baixas.

No entanto, uma comparação entre as duas políticas, como a que será feita neste trabalho, requer atenção para as particularidades de cada uma delas quanto ao público afetado. Numa transferência direta de renda, caso a focalização fosse perfeita, ou seja, todos os beneficiados têm direito e todos os que têm direito são beneficiados, todos os recursos destinados à política atingiriam a classe pobre, gerando efeitos bastante positivos em relação à desigualdade de renda e aos problemas sociais.

Devido aos problemas de focalização já discutidos isso não acontece, o que torna a eficiência desse tipo de política dependente do quão bem administrado é o programa. Quanto mais se conseguir evitar a fuga de recursos para famílias irregulares, mais perto se chegará do caso ótimo (focalização perfeita). 
Já a desoneração fiscal não possui uma classe social específica que deva atingir. Apesar de a cesta básica ser bem mais importante (em termos de fatia do consumo total) na mesa dos mais pobres, não há como evitar que as demais famílias se beneficiem de uma grande fatia do total de recursos destinados pelo Governo para a política (nesse caso, em forma de queda na arrecadação).

Este artigo inova na literatura ao realizar a comparação entre duas políticas em vigor no Brasil, o Programa Bolsa Família e a desoneração da cesta básica, considerando o problema da focalização. Uma segunda contribuição é a de estipular qual seria o valor da focalização do PBF que faria com que os resultados dos dois programas fossem equivalentes.

\section{METODOLOGIA}

Este trabalho utiliza como arcabouço teórico o modelo neoclássico com tempo discreto, economia fechada e população e tecnologia constantes.

Como o estudo não está interessado no lado das empresas, uma firma representativa é utilizada, atuando em uma estrutura de mercado em concorrência perfeita e produzindo um único bem. O governo arrecada impostos (sobre capital, consumo e renda de todas as famílias) e gasta nas transferências diretas e em suas demais obrigações, de forma que seu orçamento deve estar equilibrado.

\section{Famílias}

Existem duas famílias representativas que se diferenciam por seu nível de renda, sendo a família do tipo 1 aquela que tem direito ao Bolsa Família (considera-se elegível neste trabalho aquelas com renda familiar per capita de até R\$120,00, desconsiderando as condicionalidades por motivo de simplificação); já a família do tipo 2 é aquela que não possui direito ao benefício. A diferença de renda entre os dois tipos de famílias é incorporada no modelo por meio do parâmetro de produtividade $\zeta$, que indica o quão mais produtiva é a família do tipo 2 em relação à do tipo 1 . Outra diferença é a hipótese de que a família do tipo 1 não realiza investimentos, gastando toda a renda em consumo. As famílias do tipo 1 recebem uma parcela $\eta$ do total das transferências do PBF. As famílias do tipo 2 recebem a parcela complementar de forma indevida, representando $(1-\eta)$ do valor. As restrições orçamentárias das famílias são, portanto, para a família do tipo 1:

$$
\left(1+\tau_{c 1 t}\right) C_{1 t}=\left(1-\tau_{w}\right) w_{t} \cdot \zeta_{1} \cdot h_{1 t}+\eta \cdot P B F_{t}+t_{1 t}
$$


E para a família do tipo 2:

$$
\begin{aligned}
\left(1+\tau_{c 2 t}\right) C_{2 t}+ & K_{t+1}-(1-\delta) K_{t} \\
& =\left(1-\tau_{w}\right) w_{t} \cdot \zeta_{2} \cdot h_{2 t}+\left(1-\tau_{k}\right) \cdot r_{t} \cdot K_{t}+(1-\eta) \cdot P B F_{t}+t_{2 t}
\end{aligned}
$$

Em (2) $\zeta_{2}$ é a produtividade do trabalho da família tipo 2 e, em (1), $\zeta_{1}$ é a produtividade do trabalho da família do tipo 1 . As variáveis $h_{1 t}$ e $h_{2 t}$ são a fração do tempo que cada família gasta trabalhando.

As variáveis $C_{j t}$, $K_{t}$, e $t_{j t}$ são, respectivamente, o consumo total da família $j$ no tempo $t$, o nível de capital no tempo $t$ (que obrigatoriamente deve pertencer à família tipo 2) e as transferências governamentais para a família $j$ no tempo $t$ (que podem ser oriundas de todos os benefícios públicos com exceção do Bolsa Família, como aposentadorias, benefícios de prestação continuada, pensões etc.).

Já $\tau_{w}, \tau_{k}, \tau_{c 1}$ e $\tau_{c 2}$ representam, na sequência, as alíquotas do imposto de renda, do imposto sobre o capital e dos impostos sobre o consumo das famílias do tipo 1 e 2 . O parâmetro $\delta$ representa a depreciação do capital e $r_{t}$ é a taxa de retorno do capital.

Supondo uma utilidade logarítmica que contabiliza o bem-estar gerado tanto pelo consumo quanto pelo lazer, o processo de maximização de utilidade da família do tipo j consiste em maximizar:

$$
U j=\sum_{t=o}^{\infty} \beta^{t} \cdot\left[\ln \left(C_{j t}\right)+\gamma \ln \left(1-h_{j t}\right)\right]
$$

Sujeito à restrição orçamentária (1) para as famílias do tipo 1 ou (2) para as famílias do tipo 2.

Para as famílias do tipo 1 obtêm-se a equação de consumo-lazer:

$$
C_{1 t}=\frac{\left(1=h_{1 t}\right)\left(1-\tau_{w}\right) \cdot \zeta_{1} \cdot w_{t}}{\gamma \cdot\left(1+\tau_{c 1 t}\right)}
$$

Já para as famílias do tipo 2 obtém-se as equações de Euler e de consumo-lazer das famílias do tipo 2:

$$
\begin{gathered}
C_{2 t+1}=\frac{\left(1+\tau_{c 2 t}\right) \cdot \beta}{\left(1+\tau_{c 2 t+1}\right)}\left[1-\delta+r_{t+1}\left(1-\tau_{k}\right)\right] \cdot C_{2 t} \\
C_{2 t}=\frac{\left(1-h_{2 t}\right)\left(1-\tau_{w}\right) \cdot w_{t} \cdot \zeta_{2}}{\gamma \cdot\left(1+\tau_{c 2 t}\right)}
\end{gathered}
$$




\section{A Firma Representativa}

A função de produção da economia tem a forma Cobb-Douglas e apresenta retornos constantes de escala. Supõe-se competição perfeita, de modo que o problema da firma é maximizar o seu lucro:

$$
K_{t}^{\alpha} L_{t}^{1-\alpha}-r_{t} K_{t}-W_{t} L_{t}
$$

Em (7), $L_{t}$ é o trabalho agregado e $\alpha$ é a participação da renda do capital no produto. Após efetuar a maximização, obtemos os seguintes valores para taxa de juros e salários:

$$
\begin{gathered}
r_{t}=\alpha K_{t}^{\alpha-1} L_{t}^{1-\alpha} \\
w_{t}=(1-\alpha) K_{t}^{\alpha} L_{t}^{-\alpha}
\end{gathered}
$$

\section{Governo}

O governo mantém a seguinte restrição orçamentária equilibrada em todos os instantes:

$$
G_{t}+P B F_{t}+t_{1 t}+t_{2 t}=\tau_{c 1 t} \cdot \chi_{1} \cdot C_{1 t} C_{1_{t}}+\tau_{c 2 t} \cdot \chi_{2} \cdot C_{2 t}+\tau_{k} \cdot r_{t} \cdot K_{t}+\tau_{w} \cdot W_{t} \cdot L_{t}
$$

Em (10), $G_{t}$ é o gasto público.

\section{Equilíbrio}

A economia se equilibra quando as famílias escolhem suas respectivas sequências ótimas de consumo, lazer e investimento (no caso do tipo 2); as firmas escolhem o estoque total de trabalho e capital (que correspondem à soma do trabalho e do capital dos dois tipos de família); e o governo equilibra seu orçamento escolhendo o valor de seus gastos e das transferências de acordo com o montante arrecadado via impostos.

Portanto, o mercado de trabalho deve estar equilibrado:

$$
L_{t}=\left(\chi_{1} \cdot \zeta_{1} \cdot h_{1 t}+\chi_{2} \cdot \zeta_{2} \cdot h_{2 t}\right)
$$

Em (11), $\chi_{1}$ e $\chi_{2}$ representam a proporção de famílias do tipo 1 e 2 no total de famílias, respectivamente. $\mathrm{O}$ equilíbrio no mercado de bens implica em:

$$
C_{t}+K_{t+1}-(1-\delta) K_{t}+G_{t}=Y_{t}
$$

O consumo agregado é determinado pela seguinte expressão:

$$
C_{t}=\left(\chi_{1} \cdot C_{1 t}+\chi_{2} \cdot C_{2 t}\right)
$$




\section{CALIBRAGEM DO MODELO}

A economia brasileira foi calibrada para o ano de 2014, em função da disponibilidade das Contas Nacionais. A exceção foi a divisão entre as famílias do tipo 1 e 2, que teve por base as variáveis relacionadas à Pesquisa de Orçamentos Familiares, cuja última pesquisa disponível é de 2008/2009.

Os valores do PIB, População Economicamente Ativa, Consumo, Investimento, Gastos Governamentais e todos os dados relativos à arrecadação foram retirados das Contas Nacionais, disponibilizadas pelo Instituto Brasileiro de Geografia e Estatística (IBGE). O valor de $\alpha$, a participação da renda do capital na renda total da economia, foi calculado como a razão entre o excedente operacional bruto (rendimento das empresas) e a soma desse excedente com a remuneração total dos empregados.

$\mathrm{O}$ valor gasto com o PBF foi obtido na base de dados Ipeadata. A taxa de juros (ou taxa de rendimento do capital) corresponde à taxa básica real de juros, calculada pela diferença entre a taxa de juros média cobrada das pessoas jurídicas, de acordo com o Relatório de Inflação do Banco Central, descontada da inflação no ano de 2014 (BACEN, 2014).

Para calcular as variáveis relativas ao consumo das famílias foi utilizada a Pesquisa de Orçamentos Familiares (POF) do biênio 2008-2009, última disponibilizada pelo IBGE. Tais variáveis são: $\chi_{1}$ (proporção de famílias do tipo 1), $\chi_{2}$ (proporção de famílias tipo 2), $\zeta_{1}$ (produtividade do trabalho das famílias do tipo 1), $\zeta_{2}$ (produtividade do trabalho das famílias tipo 2), $\psi$ (fatia de renda destinada à cesta básica pela família 1) e $\varphi$ (fatia de renda destinada à cesta básica pela família 2).

É importante destacar que as famílias foram separadas entre 1 e 2 levando em conta apenas o fator renda (obviamente excluindo-se do cálculo benefício recebido pelo $\mathrm{PBF}$ ), ou seja, aquelas cuja renda familiar per capita não ultrapassa R\$ 120,00 (valor limite no ano de 2009) foram consideradas aptas a receber o benefício - famílias do tipo 1. Não foram consideradas as condicionalidades do programa por motivos de simplificação e dificuldade de manipulação dos dados caso todos esses quesitos fossem incluídos.

A razão $K / Y$ foi calculada a partir da equação de determinação dos juros da economia $r=\alpha \frac{Y}{K^{\prime}}$ Substituindo os valores de $\alpha$ e $r$, encontra-se $K / Y=4,50$ para, em seguida, determinar-se a depreciação pela expressão $\delta=\frac{I}{K / Y}=4,44 \%$. Admitindo-se $Y=1$, o trabalho agregado, $L$, foi encontrado a partir da função de produção $Y=K_{t}^{\alpha} L_{t}^{1-\alpha}$. O salário foi calculado substituindo os valores de $\alpha$ e $L$ na equação (9). 
Quanto aos tributos, cada imposto foi separado dentro das bases tributárias "Consumo", "Trabalho" e "Capital”. Nos impostos sobre o consumo foram incluídos IPI, ICMS, Cofins, PIS/Pasep, imposto de importação, Cide e outros impostos e taxas sobre a produção. Os impostos sobre o trabalho foram FGTS, contribuições previdenciárias, impostos sobre a folha de salários, IRPF e IRRF; já os impostos sobre o capital considerados foram IOF, IRPJ, CSLL, ITBI e os demais impostos sobre a renda e a propriedade.

Tabela 2 - Valores no estado estacionário inicial

\begin{tabular}{|c|c|c|}
\hline Variável & Descrição da variável & Valor \\
\hline$P B F / Y$ & Valor destinado ao programa como razão do PIB & $0,045 \%$ \\
\hline$r$ & Taxa real de juros no período (a.a.) & $9,59 \%$ \\
\hline$\alpha$ & Participação da renda do capital no produto & 0,4319 \\
\hline$I / Y$ & Investimento & $20,02 \%$ \\
\hline$G / Y$ & Gasto público & $18,66 \%$ \\
\hline$K / Y$ & Razão capital/Produto & 4,50 \\
\hline$L$ & Trabalho agregado & 0,3185 \\
\hline$\chi_{1}$ & Proporção de famílias do tipo 1 & $12,00 \%$ \\
\hline$\chi_{2}$ & Proporção de famílias do tipo 2 & $88,00 \%$ \\
\hline$C_{1}$ & Consumo das famílias do tipo 1 & 0,0778 \\
\hline$C_{2}$ & Consumo das famílias do tipo 2 & 0,6863 \\
\hline$h_{1}$ & Proporção do tempo destinado ao trabalho pela família 1 & 0,2500 \\
\hline$h_{2}$ & Proporção do tempo destinada ao trabalho pela família2 & 0,3195 \\
\hline$t_{1}$ & Transferências para as famílias tipo 1 & 0,0387 \\
\hline$t_{2}$ & Transferências para as famílias tipo 2 & 0,1580 \\
\hline$\zeta_{1}$ & Produtividade do trabalho da família tipo 1 & 0,1153 \\
\hline$\zeta_{2}$ & Produtividade do trabalho da família tipo 2 & 1,1206 \\
\hline$\tau_{w}$ & Alíquota do imposto sobre a renda do trabalho & 0,2170 \\
\hline$\tau_{k}$ & Alíquota do imposto sobre a renda do capital & 0,0942 \\
\hline$\tau_{c 1}$ & Alíquota do imposto sobre o consumo famílias tipo 1 & 0,2783 \\
\hline$\tau_{c 2}$ & Alíquota do imposto sobre o consumo famílias tipo 2 & 0,2783 \\
\hline$\psi$ & Fatia do gasto da família 1 com a cesta básica & $20,70 \%$ \\
\hline$\varphi$ & Fatia do gasto da família 2 com a cesta básica & $12,10 \%$ \\
\hline$\eta$ & Nível de focalização do Programa Bolsa Família & $54,90 \%$ \\
\hline$\delta$ & Taxa de depreciação & $4,62 \%$ \\
\hline$\beta$ & Parâmetro que mede a preferência intertemporal das famílias & 0,9464 \\
\hline$\gamma$ & Parâmetro de preferência pelo lazer & 1,2139 \\
\hline
\end{tabular}

Fonte: Elaboração dos autores. 
A alíquota do imposto de renda $\left(\tau_{w}\right)$ e sobre o capital $\left(\tau_{k}\right)$ equivalem ao total arrecadado dividido pelo que foi recebido em forma de salários e rendimento do capital, respectivamente. Já as alíquotas sobre consumo (supostamente iguais para as duas famílias no tempo inicial) são a razão entre a arrecadação total com consumo e o total consumido, ambos em proporção do PIB, logo: $\tau_{c 1}=\tau_{c 2}$.

O valor do nível de focalização atual do PBF, $\eta=54,9 \%$ foi retirado de Soares, Ribas e Soares (2009). Isso significa que 54,9\% dos beneficiários são elegíveis para tal, enquanto os outros $45,1 \%$ não têm direito e correspondem a problemas de focalização.

Admite-se que as famílias são dotadas de uma unidade de tempo que pode ser alocada para trabalho ou lazer. No caso das famílias do tipo 1, as horas de trabalho

foram fixadas em $44 \mathrm{~h}$ semanais, de modo que $h_{1}=\frac{44}{176}=0,25$. Por fim, as variáveis $\beta, \gamma, c_{1}, c_{2}, h_{2}, t_{1}$ e $t_{2}$ foram calculadas a partir de um sistema não linear que inclui as versões das equações (1), (2), (4) a (6), (11) e (13) no estado estacionário. A Tabela 2 resume a calibragem.

\section{RESULTADOS}

Com o propósito de analisar os efeitos das políticas estudadas são necessárias duas suposições simplificadoras. A primeira hipótese é a de que a desoneração fiscal dos alimentos será repassada integralmente ao consumidor. Outra suposição é a de que o aumento dos benefícios do PBF não altera sua focalização.

Há também duas limitações importantes do modelo. A primeira é que ele não consegue captar a ineficiência gerada pela desoneração da cesta básica ao diferenciar as alíquotas entre dos produtos desonerados em relação aos demais bens. Outra limitação é que o modelo não contempla a evasão fiscal, o que também diminui a efetividade da desoneração da cesta básica.

A primeira simulação trata dos efeitos econômicos da desoneração da cesta básica. A segunda simulação supõe que, ao invés de reduzir a tributação dos alimentos, o governo escolhe aumentar o valor do Programa Bolsa Família, de modo que o montante gasto com o aumento dos benefícios deve ser igual à queda na arrecadação decorrente da política de desoneração da cesta básica. Isso é necessário para que as políticas tenham o mesmo custo, fazendo com que a comparação entre as duas dependa apenas de seus benefícios sobre a utilidade.

\section{Desoneração da Cesta Básica}

A primeira proposta é a redução do imposto sobre os bens da cesta básica. No modelo essa política é incorporada por meio da variação dos valores de $\tau_{c 1}$ e $\tau_{c 2}$. 
Sejam $\tau c_{c b}$ e $\tau c_{\text {mis }}$, respectivamente, as alíquotas sobre o conjunto de bens que compõem a cesta básica e a alíquota sobre os demais bens, de modo que as alíquotas totais são:

$$
\begin{gathered}
\tau_{c 1}=\varphi \cdot \tau c_{c b}+(1-\varphi) \cdot \tau c_{m i s} \\
\tau_{c 2}=\psi \cdot \tau c_{c b}+(1-\psi) \cdot \tau c_{m i s}
\end{gathered}
$$

Em (14), $\varphi$ é a proporção da renda da família tipo 1 gasta em cesta básica, e em (15) $\psi$ é a mesma proporção para a família do tipo 2.

$O$ valor de $\tau_{c 1}$ e $\tau_{c 2}$ no estado estacionário inicial já é conhecido da calibragem do modelo, enquanto o valor de $\tau c_{c b}$ é calculado a partir de Nota Técnica do DIEESE (2013), que calcula a alíquota dos insumos indiretos sobre a cesta básica (valor igual a $3,82 \%)$. Conhecendo todos esses valores é possível recuperar o valor de $\tau c_{\text {mis }}$. Obter esses valores é importante porque, após a desoneração, $\tau c_{c b}$ passará a ser igual a zero, logo:

$$
\begin{gathered}
\tau_{c 1_{-} D C B}=(1-\varphi) \cdot \tau c_{m i s} \\
\tau_{c 2_{-} D C B}=(1-\psi) \cdot \tau c_{m i s}
\end{gathered}
$$

Usam-se $\tau_{c 1_{-} D C B}$ e $\tau_{c 2_{2} D C B}$ para representar os valores das alíquotas após a desoneração fiscal. Esses valores se diferenciam devido ao peso de ponderação que cada família dá ao custo da cesta básica.

Dessa forma, a simulação consiste em substituir $\tau_{c 1}=\tau_{c 2}=27,83 \%$ por $\tau_{c 2_{-} D C B}=27,37 \%$ e $\tau_{c 1_{-} D C B}=27,04 \%$ respectivamente, o que equivale, em termos econômicos, à retirada dos impostos federais sobre a cesta básica.

Para manter o equilíbrio no orçamento público, supõe-se que o Governo financie suas políticas por meio de reduções nas transferências para as famílias do tipo $2\left(t_{2}\right)$. Os resultados macroeconômicos podem ser vistos no Gráfico 1.

A desoneração fiscal representa um impulso à economia. A redução da tributação eleva o consumo, já que reduz o custo de consumir para as famílias. A elevação do consumo aumenta a produção, incrementando também dois fatores, trabalho e capital. O consumo se eleva mais do que as demais variáveis porque ocorre um deslocamento do investimento para o consumo, uma vez que, num primeiro momento, consumir se torna mais barato do que investir, e porque as famílias preferem não aumentar tanto a oferta de trabalho, dadas as suas preferências por lazer. 
Gráfico 1 - Efeitos da desoneração da cesta básica nas variáveis macroeconômicas

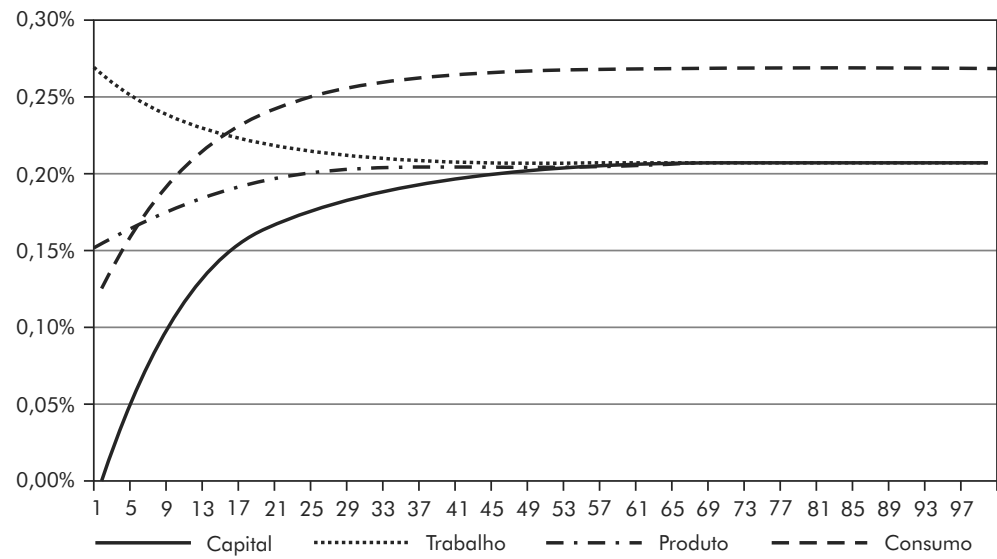

Fonte: Elaboração própria.

O Gráfico 2 apresenta os resultados desagregados por família para o consumo e lazer.

Gráfico 2 - Trajetória do consumo e lazer das famílias após desoneração da cesta básica

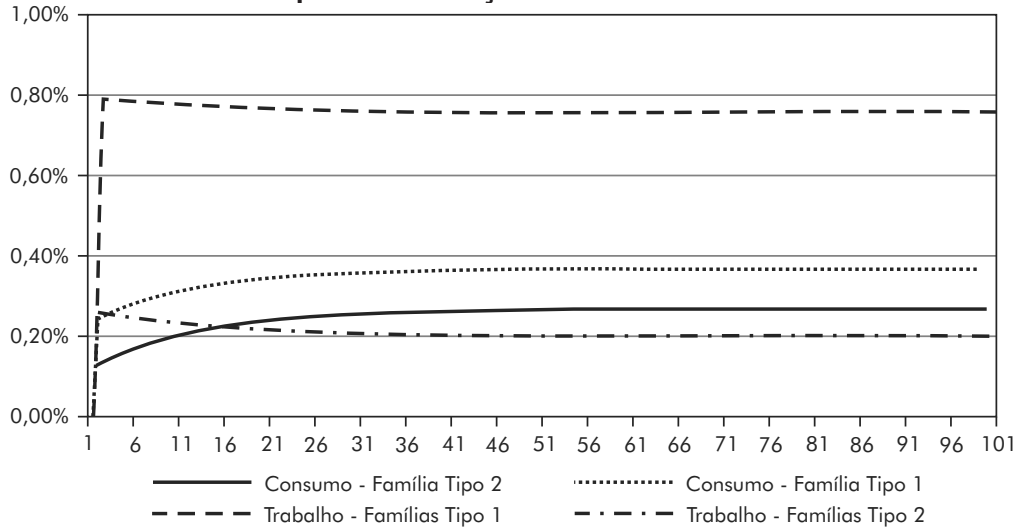

Fonte: Elaboração própria.

O consumo cresce impulsionado pela redução da tributação dos produtos desonerados. O total consumido pelas famílias do tipo 1 sobe $0,37 \%$, e o consumido por aquelas do tipo 2 se eleva em $0,27 \%$. O motivo de o crescimento ser bem maior na classe pobre é que esta destina uma fatia de $20,7 \%$ de sua renda para a cesta básica, enquanto as famílias do tipo 2 destinam para esse tipo de bem apenas 12,1\% de seus rendimentos, de forma que a redução nos preços afeta bem mais as famílias tipo 1. 
Já em relação ao trabalho, com o aumento da produção, a demanda por trabalho cresce. Do lado da oferta, a redução da tributação impacta na escolha consumo-lazer, fazendo com que as famílias aumentem a oferta de trabalho. Como a redução da tributação foi maior nas famílias do tipo 1, são essas que mais elevam a oferta de trabalho.

\section{Aumento no Programa Bolsa Família}

Para efeito de comparação entre as duas políticas, supõe-se que o Governo elevará a despesa com o PBF em $0,028 \%$ do PIB, exatamente o mesmo valor da renúncia fiscal da desoneração da cesta básica. Novamente supõe-se que esse valor será compensado no orçamento público por redução em $t_{2}$.

O Gráfico 3 apresenta as trajetórias das variáveis macroeconômicas.

\section{Gráfico 3 - Efeitos do aumento do PBF nas variáveis macroeconômicas}

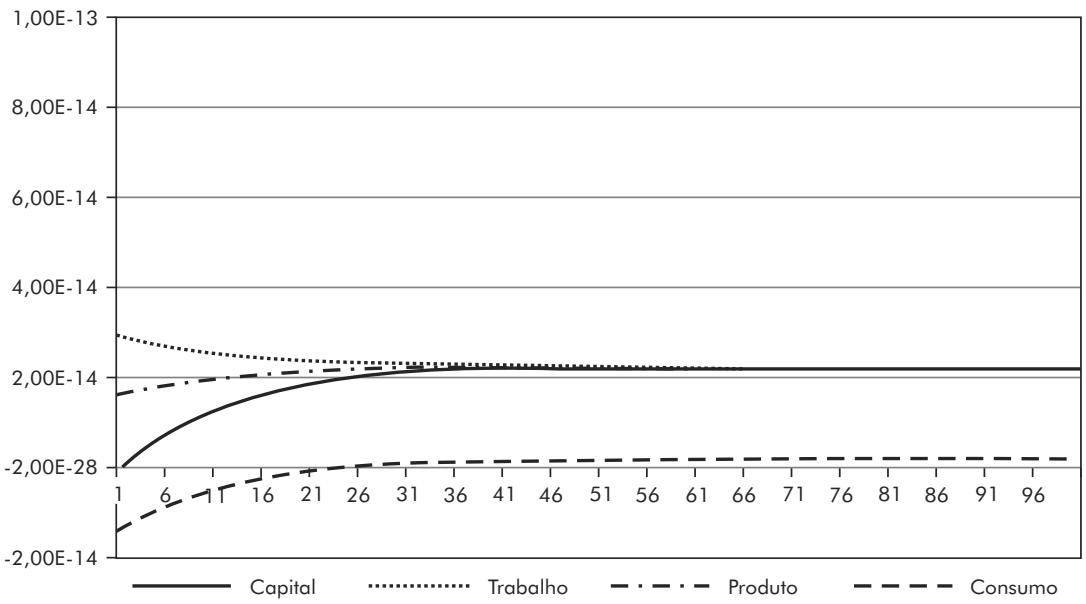

Fonte: Elaboração própria.

A elevação do valor do PBF não causa impacto macroeconômico nesse modelo, já que ocorre apenas uma troca entre transferências. As transferências do PBF aumentam e a transferência $t_{2}$ diminui no mesmo montante.

O contrário ocorre com as variáveis desagregadas que sofrem variações significativas, como mostra o Gráfico 4.

Pode-se perceber que o impacto dessa política sobre o consumo teve um viés bem mais pró-pobre. O consumo da família do tipo 1 sobe em 5,6\%, mais do que dez vezes o aumento proporcionado pela desoneração. Isso se deve ao fato de que, apesar de destinar uma fatia menor de sua renda para a cesta básica, as famílias do tipo 2, graças a seu maior número e à maior quantidade consumida em termos absolutos, apodera-se da maior parte dos benefícios da desoneração. Por outro lado, mesmo com os problemas 
de focalização já comentados, a elevação do $\mathrm{PBF}$ destina a maior parte dos recursos às famílias do tipo 1 (mais precisamente $54,9 \%$ ), de forma que o resultado sobre o consumo destas é bem mais elevado.

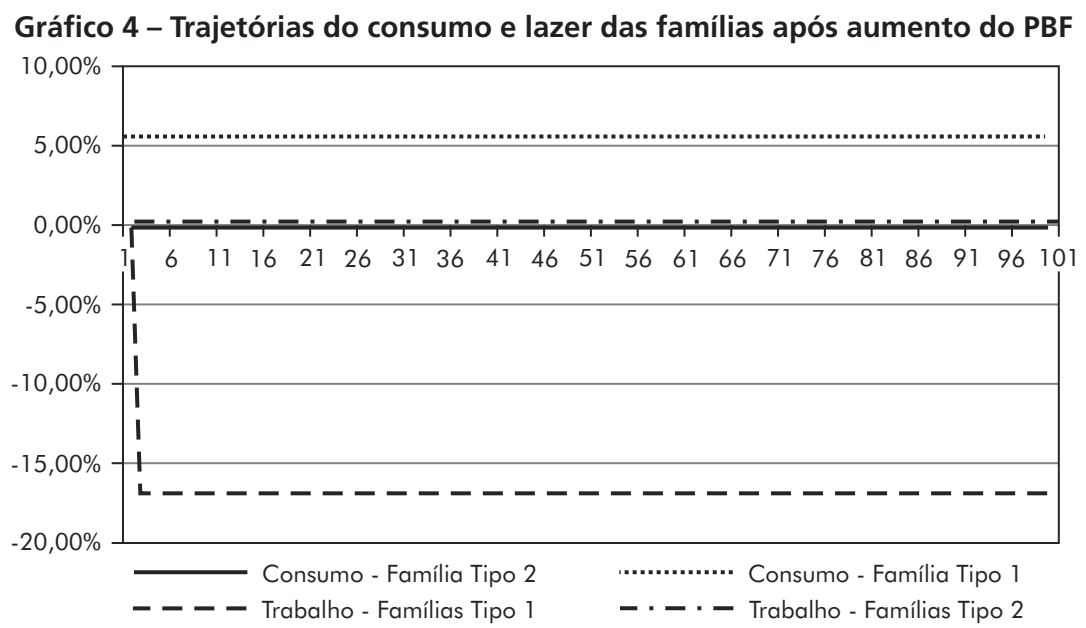

Fonte: Elaboração própria.

Já as famílias do tipo 2 mantêm o consumo em um nível praticamente estável, com uma pequena redução de $0,09 \%$, já que, por um lado, perdem com a redução de $t_{2}$, mas, por outro, recuperam um pouco com o recebimento de $(1-\eta) \cdot P B F$. A política não tem efeitos sobre o consumo desse tipo de família.

Já o efeito sobre o trabalho é o inverso da desoneração da cesta básica. Como o valor do PBF sobe $60 \%$, a renda das famílias do tipo 1 se eleva substancialmente, permitindo que esse grupo aumente o seu consumo e também reduza a oferta de trabalho. Já as famílias do tipo 2 passam a receber um valor um pouco menor de transferências, de modo que, para compensar, precisam reduzir um pouco o consumo e aumentar levemente a oferta de trabalho, que sobe $0,18 \%$.

Com relação à utilidade, o Gráfico 5 compara a utilidade das famílias dos tipos $1 \mathrm{e}$ 2 com a desoneração da cesta básica e aumento do PBF.

Percebe-se que a medida de elevação do PBF é bem mais eficiente quando o critério são os ganhos de bem-estar das famílias de baixa renda. A razão para isso é que as transferências diretas têm um público-alvo mais bem definido, possibilitando que a maior parte dos recursos seja destinada a este (apesar dos problemas de focalização). No caso da desoneração, mesmo se tratando de um conjunto de bens de consumo popular, tais bens também são consumidos pelas famílias de renda mais alta que também se apropriam de uma grande fatia dos recursos destinados à política. 
Gráfico 5 - Trajetórias da utilidade de cada família após cada política
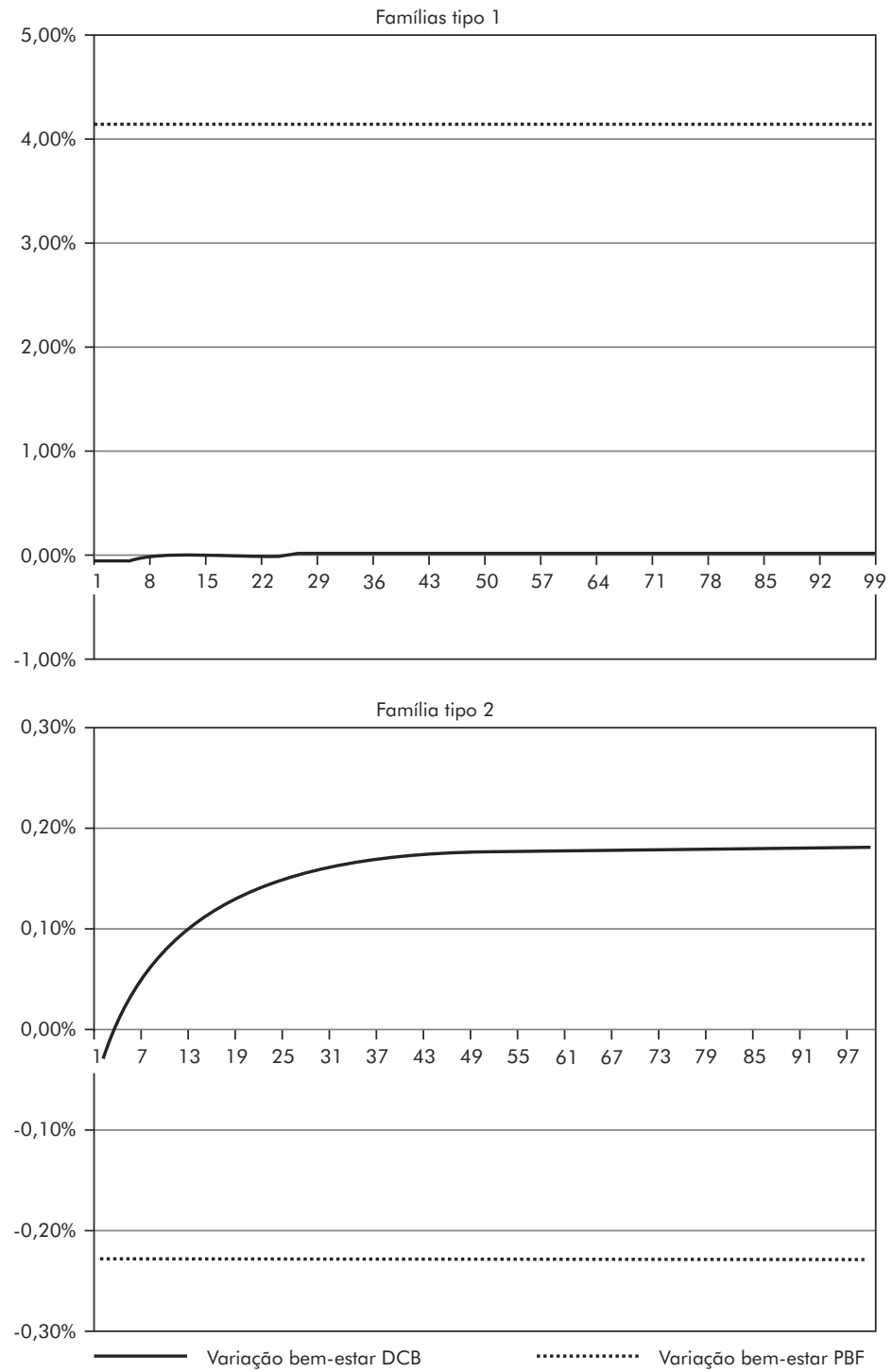

Fonte: Elaboração própria.

Em termos de valor presente da utilidade, no caso da família do tipo 1, a desoneração da cesta básica proporcionou um ganho de 0,08\%, e o aumento do Programa Bolsa Família um ganho de $92,4 \%$. Para a família do tipo 2, a desoneração da cesta básica permitiu um ganho de $2,4 \%$ e, no caso do aumento do Programa Bolsa Família, uma perda de $5,1 \%$. 
Caso a focalização fosse perfeita, os efeitos seriam ainda maiores sobre a família do tipo 1, que receberia todo o montante de recursos. No entanto, para a família do tipo 2 os resultados levariam à piora do bem-estar, que ficaria apenas com o custo da redução de $t_{2}$.

\section{Cálculo do nível de focalização que torna as políticas indiferentes (Análise de sensibilidade - famílias tipo 1)}

O valor de $\eta$ que iguala os efeitos das duas políticas é um dado importante por ser uma medida que pode determinar qual política seria a mais correta. Seja então $\bar{\eta}$ o nível de focalização de indiferença entre as duas políticas. Um nível de focalização mais baixo que $\bar{\eta}$ sinaliza que a desoneração da cesta básica pode ser a medida mais adequada, enquanto que, se o nível de focalização for superior a $\bar{\eta}$ um incremento no Programa Bolsa Família seria mais desejável.

$O$ valor de $\bar{\eta}$ é encontrado calculando-se qual o valor de $\eta$ que proporciona o mesmo valor presente da utilidade das famílias do tipo 1 , considerando as duas políticas alternativas.

Nesse caso a simulação aponta $\bar{\eta}=35,4 \%$ como o valor de equilíbrio, que significa que,se o nível de focalização cair para $35,4 \%$ por conta do aumento do valor do PBF, o efeito sobre a utilidade da família tipo 1 será equivalente ao de uma desoneração dos impostos federais da cesta básica. Esse resultado pode ser considerado positivo quando é comparado aos dados da literatura para a economia brasileira. Como já comentado, os trabalhos da área sempre encontram níveis de focalização superiores a 53\%, o que representa uma margem segura para que o valor real esteja acima dos 35,4\% encontrados aqui.

Essa margem também é importante pelo fato de alguns trabalhos, como os de Soares, Ribas e Soares (2009), argumentarem que aumentos no tamanho do programa levam a quedas no nível de focalização. Com uma diferença de mais de $18 \%$ (segundo a literatura) entre o nível corrente de focalização e o nível mínimo que torna a política atrativa, o Governo pode optar por elevar o programa (mesmo arriscando-se a gerar quedas no nível de focalização) e obter resultados melhores do que com a desoneração da cesta básica.

\section{CONSIDERAÇÕES FINAIS}

O trabalho sugere a maior eficácia do aumento do PBF em comparação à desoneração da cesta básica quando o objetivo é a elevação da utilidade dos mais pobres. Esse resultado pode ser explicado pela característica de transferência direta de renda para a população e pela razoável focalização do programa. 
Como as políticas foram financiadas por meio da redução das transferências para as famílias do tipo 2, ambas geraram efeitos positivos na utilidade da família 1, no entanto, a desoneração tem um efeito menor pelo fato de a maior parte do consumo de produtos desonerados ser realizada pelas famílias do tipo 2, que possuem renda mais elevada. No caso do programa Bolsa Família, mesmo com os problemas de focalização, a maior parte da renda se destina aos mais pobres.

Esse resultado se mantém mesmo com a queda do nível de focalização do PBF até o valor de $35,4 \%$. Nesse nível de focalização a utilidade dos mais pobres será equivalente ao que teria sido obtido com a desoneração fiscal. Esse resultado, quando comparado ao grau de focalização do PBF calculado para a economia brasileira, mostra que ainda há espaço para o crescimento do programa, mesmo que este gere perda de foco, pois o programa ainda se encontra a uma distância segura de seu nível mínimo de atratividade.

Como em todos os modelos teóricos, existem aqui simplificações e limitações, algumas delas podem ser corrigidas em trabalhos futuros, já outras dificilmente poderiam ser incorporadas num modelo atual devido a sua complexidade ou ausência de dados. Sugere-se para pesquisas futuras o uso de mais classes de famílias divididas não só por níveis de renda, mas também por suas características sociais, que também são importantes na formulação de políticas de combate à pobreza. Outra possibilidade interessante é incluir outras formas de financiamento das políticas como, por exemplo, a possibilidade de endividamento público.

Por fim, apesar dos problemas de desvio de recursos e das dificuldades administrativas impedirem uma melhor focalização do PBF, este ainda mantém um nível relativamente bom se comparado ao mínimo necessário para que essa seja uma política viável.

\section{REFERÊNCIAS}

ANUATTI-NETO, F; FERNANDES, R.; PAZELLO, E. T. Poverty alleviation policies: the problem of targeting when income is not observed. Texto para Discussão, Ribeirão Preto, FEARP, n. 17, 2001.

ARAÚJO, L. A.; LIMA, J. P. Transferências de renda e emprego públicos na economia sem produção do semiárido nordestino. Planejamento e Políticas Públicas, v. 33, n. 2, p. 45-78, 2009.

CASTRO, H.; SANTANA, M.; STEPHANOU, M. Percepções sobre o Programa Bolsa Família na sociedade brasileira. Opinião Pública, v. 15, n. 2, p. 333-355, 2009.

DIEESE - DEPARTAMENTO INTERSINDICAL DE ESTATÍSTICA E ESTUDOS SOCIOECONÔMICOS. A desoneração dos produtos da cesta básica. Nota Técnica Dieese, n 120, 2013. Disponível em: <https://www.dieese.org.br/notatecnica/2013/notaTec120DesoneracaoCestaBasica.pdf>. Acesso em: 30 jan. 2019. 
GLEWWE, P.; KASSOUF, A. L. The impact of the Bolsa Escola/Família conditional cash transfer program enrollment, dropout rates and grade promotion in Brazil. Journal of Development Economics, v. 22, n. 3, p. 505-517, 2012.

GOMES, G. M. Velhas secas em novos sertões. Brasília: IPEA, 2001.

IPEA - INSTITUTO DE PESQUISA ECONÔMICA E APLICADA. Bolsa Família 2003-2010: Avanços e desafios. v. 2. Brasília, DF: IPEA, 2010.

IPEA - INSTITUTO DE PESQUISA ECONÔMICA E APLICADA. Ipeadata. 2014. Disponível em: <http://www.ipeadata.gov.br/>. Acesso em: 21 ago. 2014.

MEDEIROS, M.; BRITTO, T.; SOARES, F. Programas focalizados de transferência de renda no Brasil, contribuições para o debate. Texto para Discussão, IPEA, n 1.283, 2007.

MOURÃO, L.; FERREIRA, M. C.; JESES, A. Evaluation of the Brazilian family grant program: A quasi-experimental Study in state of Rio de Janeiro. Psicologia: reflexão e crítica, v. 14, n. 4, p. 719-729, 2012.

OLIVEIRA, F. et al. Programa Bolsa Família e estado nutricional infantil: desafios estratégicos. Ciência e Saúde Coletiva, v. 16, n. 7, p. 3307-3316, 2011.

PAES, N. L.; SIQUEIRA, M. L. Renda básica da cidadania versus imposto de Renda negativo: O papel dos custos de focalização. Estudos Econômicos, v. 18, n. 3, p. 583-610, 2008.

PAES, N. L.; BUGARIN, M. Parâmetros tributários da economia brasileira. Estudos Econômicos, v. 34, n. 4, p. 699-720, 2006.

SANTOS, C.; FERREIRA FILHO, J. Efeitos potenciais da política tributária sobre o consumo de alimentos e insumos agropecuários: uma análise de equilíbrio geral inter-regional. Revista de Estudos Regionais, v. 18, n. 4, p. 921-962, 2007.

SANTOS, V.F.; VIEIRA, W. C.; REIS, B. Effects of alternative policies on income redistribution: evidence from Brazil. Development Policy Review, v. 42, n. 3, p. 601-616, 2009.

SILVEIRA-NETO, R. M. "Impacto do Programa Bolsa Família dobre a frequência à escola: estimativas a partir de informações da Pesquisa Nacional por Amostra de Domicílio (PNAD)". In: IPEA - INSTITUTO DE PESQUISA ECONÔMICA E APLICADA. Bolsa Família 20032010: avanços e desafios. Brasília: IPEA, 2010, p. 53-72.

SIQUEIRA, R. B. Redistributive effects of alternative indirect tax reforms for Brazil. Economia Aplicada, v. 27, n. 2, p. 244-265, 1997.

SOARES, S. et al. "Os impactos do Benefício do Programa Bolsa Família sobre a desigualdade e a pobreza”. In: IPEA - INSTITUTO DE PESQUISA ECONÔMICA E APLICADA. Bolsa Família 2003-2010: avanços e desafios. Brasília: IPEA, 2010, p. 25-52.

SOARES, S.; RIBAS, R.; SOARES, F. Focalização e cobertura do Programa Bolsa Família: qual o significado dos 11 milhões de famílias? Rio de Janeiro: IPEA, 2009.

TAVARES, P. A. et al. Uma avaliação do Programa Bolsa Família: focalização e impacto na distribuição de renda e pobreza. Pesquisa e Planejamento Econômico, v. 34, n. 1, p. 25-58, 2009.

TUPY, I. S.; TOYOSHIMA, S. H. Impacto dos programas governamentais de transferência de renda sobre a economia do vale do Jequitinhonha. In: ENCONTRO NACIONAL DE ECONOMIA, 16., Foz do Iguaçu, PR, 2013.

VAN DER NOORD, P.; HEADY, C. Surveillance of tax policies: a synthesis of findings in economic surveys. Working Paper, OECD Economic Department, 2001. 